\title{
Pornotopias - espaço, mídias e sexualidade
}

\section{Luiz Felipe Zago}

\section{Resumo}

Analisa-se articulação entre um site de

relacionamentos, espaço urbano e experiências

de (homo)sexualidade, privilegiando o potencial

comunicativo trazido pela internet e sublinhando

os traços culturais e históricos da sociabilidade

gay. Usam-se trechos de perfis online e entrevistas

realizadas com usuários do site. Toma-se a internet

como uma heterotopia, e, especificamente, 0 site de

relacionamentos é abordado por meio do conceito

de pornotopia. Mencionam-se as relações entre segurança, discrição e violência na ocupação de determinados espaços. Conclui-se que os usos da internet feitos pelos entrevistados respondem às constrições de uma sexualidade historicamente estigmatizada.

\section{Palavras-Chave}

Sexualidade. Espaço urbano. Site de relacionamento.

Luiz Felipe Zago I professorluizfelipezago@gmail.com Doutor em Educação pelo Programa de Pós-Graduação da Faculdade de Educação da Universidade Federal do Rio Grande do Sul - UFRGS, Brasil. Professor Permanente do Programa de Pós-Graduação em Educação da Universidade Luterana do Brasil - Ulbra, na Linha de Pesquisa em Pedagogia e Políticas da Diferença.

\section{Introdução - ou a sexualidade na comunicação}

Este artigo é produto parcial de uma pesquisa que analisa os modos como alguns homens gays brasileiros fazem uso de um site de relacionamentos, o Manhunt $^{1}$, como espaço de sociabilidade na busca de parceiros afetivos e sexuais. Utilizou-se a entrevista semiestruturada online, via MSN Messenger à época, e off-line, em encontros corpo a corpo, com usuários do site que aceitaram engajar-se em conversas sobre internet e sexualidade 2 . No site, é possível construir um perfil online, publicar fotografias do corpo e escrever textos sobre os objetivos de usar o Manhunt. Pode-se também enviar e receber mensagens de outros usuários. Para a pesquisa, foram arquivados perfis online de usuários, cujos trechos figurarão aqui anonimamente ${ }^{3}$. 0 Manhunt funciona como uma rede social, de modo análogo ao Facebook (RECUERO, 2009); porém, a proposta do Manhunt é focada em promover encontros entre homens para práticas sexuais e relacionamentos afetivos, como mostrase em seguida. 
Toma-se a internet como uma heterotopia (LEMOS, 2010), espaço que "tem como regra justapor em um lugar real vários espaços que, normalmente, seriam ou deveriam ser incompatíveis", como propõe Michel Foucault (2013, p. 24). Entre esses vários espaços justapostos que caracterizariam a internet como heterotopia, emergem os sites de relacionamento - e, mais recentemente, os aplicativos geolocalizados para smartphones - como pornotopias": "heterotopia própria do capitalismo tardio", a qual tem "capacidade de estabelecer relações singulares entre espaço, sexualidade, prazer e tecnologia (...) produzindo a subjetividade sexual como um derivado de suas operações espaciais" ${ }^{5}$, na ousada proposição de Paul Beatriz Preciado (2010, p. 120). Argumentase que a internet pode ser pensada como heterotopia e, na sua esteira, especificamente 0 site Manhunt pode ser considerado uma pornotopia para os homens usuários, com suas singulares possibilidades tecnológicas de conexão e de mediação entre indivíduos por meio da web.

Considera-se a emergência da internet a par do conjunto de espaços de sociabilidade para homens gays, além da rede mundial de computadores e previamente existentes à popularização da internet (GREEN, 2000; TERTO JR., 1996; TRINDADE, 2004). Esses outros espaços coexistem com os sites de relacionamento e aplicativos da atual sociabilidade de homens gays brasileiros. Nessa direção, busca-se inventariar algumas relações entre espaço urbano e (homo)sexualidade, inserindo a internet em um "mapa físico e também subjetivo" (INGRAM; BOUTHILLETTE; RETTER, 1997, p. 55) compartilhado por homens gays, mapa de acordo com o qual se dá a busca por parceiros.

Neste exercício, sublinhar-se-á o potencial comunicativo dos sites de relacionamento como pornotopias, mencionando algumas marcas culturais e políticas constituintes de sociabilidade através da internet, de acordo com os entrevistados. Pode-se sugerir que, ao utilizarem Manhunt como espaço de sociabilidade, os usuários demandam a invisibilidade e discrição em relação às identidades gays (ZAG0, 2013; SEDGWICK, 2007) e buscam segurança contra a violência por discriminação (MISKOLCI, 2015; ERIBON, 2008). Entretanto, também se verifica

www.manhunt.net

Ao todo, foram realizadas cento e três (103) entrevistas online. Desse total, restaram quarenta e seis (46) que apresentaram diálogos contínuos. Foram feitas cinco (5) entrevistas off-line em São Paulo, Brasília e Rio de Janeiro.

3 Ao todo, foram arquivados trezentos e dois (302) perfis online.

Considera-se, aqui, o conceito de pornotopia conforme trabalhado por Paul Beatriz Preciado. Entretanto, cabe mencionar que este termo surgiu na obra de Steven Marcus, The Other Victorians: a Study of Sexuality and Pornography in Mid-NineteenthCentury England, publicado na década de 1960 nos Estados Unidos.

As traduções de obras em língua estrangeira para o português são de responsabilidade do/a autor/a. 
que é precisamente dentro do espaço do Manhunt onde acontecem práticas violentas de exclusão entre os próprios usuários.

\section{As pornotopias do presente}

As traduções livres do nome Manhunt podem ser "caça de homem" (no sentido de ser uma prática viril) ou "caça ao homem" (no sentido de lançar-se à busca por um homem). Isto é, os relacionamentos que 0 site pretende promover são entre homens, de modo específico, e têm a característica de busca, de disputa, de caça.

\section{Manhunt coexiste com outros sites de} relacionamento, tanto aqueles voltados para gays quanto os direcionados para heterossexuais (cf. PELÚCIO, 2015). Além dos sites, vem crescendo 0 uso dos aplicativos geolocalizados desenvolvidos para smartphones e tablets - como 0 aplicativo Grindr, especificamente voltado para homens gays, e o Tinder, que vincula perfis do Facebook -, também caracterizados como "mídias locativas" (LEMOS, 2010, p. 61). A especificidade dos aplicativos geolocalizados é situar a localização de seus usuários de modo a mostrar indivíduos geograficamente próximos, com precisão acurada, graças à tecnologia do Global Positioning System (DUARTE; FIRMINO, 2010; MISKOLCI, 2015). 0 uso dos aplicativos geolocalizados mistura experiências espaciais com tecnologias de comunicação, produzindo "infiltrações entre diferentes espacialidades físicas e informacionais através de redes digitais de comunicação" (DUARTE; FIRMINO, 2010, p. 108).

Por outro lado, pode-se referir como semelhanças entre os aplicativos geolocalizados e os sites de relacionamento o fato de os usuários escolherem imagens e palavras (geralmente para caracterizar seus corpos) na construção de perfis online e mostrarem-se aos demais, além da utilização da internet como meio de comunicação na troca de mensagens. Ainda, é comum entre os usos dos sites de relacionamento e dos aplicativos geolocalizados a expectativa de "caçar" online parceiros sexuais e afetivos. Nesse sentido, tanto os sites de relacionamento quanto os aplicativos geolocalizados constituem-se em espaços de disputa em torno dos corpos e das sexualidades, lançando mão da tecnologia da internet.

Quando perguntado em uma entrevista online sobre sua circulação em outros espaços além da internet para conhecer outros homens gays, 0 usuário do Manhunt Daydreamer ${ }^{6}$, com 23 anos na época, respondeu o seguinte: "geralmente saio com grupos grandes de amigos... até que conheço gente por aí, mas o Manhunt é mais uma forma”.

Pesquisador: 0 Manhunt é mais um espaço dentre outros, é isso?

Daydreamer: É, de certa forma sim. Claro que é mais específico, e por isso mesmo, mais com- 
plicado conhecer alguém... porque grande parte tá interessada só no sexo mesmo.

Pesquisador: Bom, mas uma boate ou um bar gay também são específicos.

Daydreamer: Sim, sim. Mas tem gente que vai [para boates ou bares gays] pra conversar, pra trabalhar, pra se pegar, pra dançar, pra beber. 0 Manhunt é mais focado em sexo, até por causa do nome... é uma rede de 'paquera'... Mas eu encontrei gente ali que às vezes não era tão seguro da própria sexualidade pra ir a uma boate gay. E usava o Manhunt pra encontrar outros gays e socializar.

Segundo Daydreamer, o Manhunt tem uma proposta e um público-alvo: é um site de encontros sexuais para homens gays. Por essa razão, abundam imagens de corpos nus, de partes de corpos nus, nos perfis online dos usuários. Talvez no site eles possam experimentar algo dos seus corpos e sexualidades que em outros espaços eles não podem; talvez haja relações peculiares entre espaço e sociabilidade sexual no Manhunt. É nesse "espaço outro" do site onde algumas regras impeditivas parecem estar suspensas (a suposta obscenidade dos corpos nus é generalizada) e onde algumas experiências relacionadas ao espaço, aos corpos e às sexualidades poderão surgir para esses homens.

Mais importante ainda é Daydreamer dizer que há homens que usam o espaço do Manhunt não apenas para "caçar", como o nome do site sugere, mas, sobretudo, para "socializar", ou seja, para estar junto de outros homens. Há talvez um escape à proposta estrita que o Manhunt oferece: procura-se sexo, sim, mas, simultaneamente, procura-se por algo além e aquém de sexo, ou algo através do sexo. Esse algo além, aquém e através das práticas sexuais entre homens é que pode ser chamado de sociabilidade, como Daydreamer sugeriu - ou de être-ensemble, como propõe Michel Maffesoli (2005); porém, conforme Daydreamer, tal sociabilidade pode ser produto de certo receio, medo ou sensação de insegurança que impedem esses homens de frequentarem espaços ditos tradicionais para busca de parceiros.

Em outro trecho de sua entrevista online, Daydreamer diz o seguinte: "na minha adolescência a internet era como a praça da cidade onde todo mundo se encontrava". Ecoa aqui algo que Paulo Vaz (2004, p. 225) já entrevia como uma nova topologia, nos primórdios da Web 2.0: "Eis o sonho: com a internet, enfim, a troca de mensagens assemelha-se a um diálogo ou ao que ocorre numa praça ou numa festa". Pode-se sugerir que analogias espaciais nas pesquisas sobre sites de relacionamento e sexualidade são bastante recorrentes. Larissa Pelúcio, ao analisar os usos feitos do site Ashley Madison entre homens brasileiros, escreve sobre seu ofício de pesquisadora: "Todos os dias entrar no site (...). Abri naquele site dois perfis (...) Havia ainda a possibilidade de estar a sós numa imersão na tela" (PELÚCIO, 2015, p. 32-33-41, grifos meus). Em sua etnografia junto a homens paulistanos usuários de aplicativos de busca de parceiros sexuais, Richard Miskolci (2015, p. 76) denota: "Qualquer que seja 0 
intuito inicial do usuário, ao entrar online ele será facilmente induzido a criar um perfil em que comodificará a si mesmo para entrar em uma espécie de mercado sexual”; e, mais adiante, 0 mesmo autor propõe: "0 uso das mídias digitais, e dos aplicativos em particular, envolve alocar o desejo por outros homens em um espaço e tempo que não interfiram em vidas vividas dentro das premissas heterossexuais" (MISKOLCI, 2015, p. 79 , grifos meus).

Tomando a internet como uma "praça", como heterotopia, como um espaço de coabitação de diferentes grupos de pessoas, a rede mundial de computadores se torna um espaço de disputa e de coexistência, seio onde habitam vários indivíduos que buscam por relações com outros. Pelúcio e Miskolci dão pistas sobre a dinâmica social que envolve a busca por parceiros e as experiências de sexualidade através das mídias digitais: intensa integração tecnológica (imersão na tela, abertura de perfis), conversão do perfil online em uma mercadoria sexual (comodificação de si no mercado sexual), deslocamento da expressão do desejo homossexual para um espaço protegido pelo suposto anonimato (busca por parceiros homens nas mídias digitais, e não em bares, boates, bairros ou festas).

Pode-se sugerir que a internet funcione como heterotopia (LEMOS, 2010), em primeiro lugar, porque é um lugar de justaposição de outros espaços a priori incompatíveis (FOUCAULT, 2013). Segundo, porque a internet compõe a categoria das heterotopias que "têm em comum serem lugares onde estou e não estou, como 0 espelho e o cemitério; ou onde sou outro como na casa de tolerância (...) ou na festa (...). Eles ritualizam cortes, limiares, desvios e os localizam" (DÉFERT, 2013, p. 37, grifo meu). Nessa direção, a internet criaria fluxos de comunicação que "perpassam pelo espaço físico criando novas espacialidades que não podem ser pensadas ao tentar-se isolar sua parcela 'física' e sua parcela 'informacional'” (FIRMINO; DUARTE, 2010, p. 110). A internet é uma heterotopia na qual se instala uma cesura; espaço onde se entra e, uma vez lá 'dentro', abre-se a possibilidade de um indivíduo tornar-se diferente do que é em outros espaços. Ademais, é traço característico das heterotopias o fato de serem "a contestação de todos os outros espaços" (FOUCAULT, 2013, p. 28): estranho espaço onde 0 anonimato pode deslocar uma identidade sem que seja necessário assumi-la para nele adentrar - ou, precisamente, um espaço onde assumimos identidades diferentes daquelas que assumimos em outros espaços.

Assim, podemos circunscrever de modo mais preciso 0 contexto de utilização das possibilidades técnicas da internet para a exibição de corpos, para a sociabilidade e para a busca de parceiros sexuais e afetivos por meio do conceito de pornotopia, cunhado por Paul Beatriz Preciado (2010). Em uma pesquisa histórica minuciosa acerca da emergência da revista Playboy no contexto estadunidense da Guerra Fria, Preciado (2010, p. 118) nomeia de "primeiro bordel 
multimídia da história" o império de comunicação construído por Hugh Hefner, dono da Playboy, do qual faziam parte não apenas a revista, mas também a Mansão Playboy, o Club Playboy, 0 jato particular DC-9 de Hefner (o Big Bunny), o iate Playboy, os canais de televisão - e, mais recentemente, os sites na internet. Lembremos: a Mansão Playboy surgiu como um primeiro 'reality-show' rodado em uma casa habitada por mulheres em trajes de "coelhinhas", com piscinas, salas de festas, salões de jogos, vários quartos - e, o mais importante, dezenas de câmeras que filmavam e fotografavam tudo o que acontecia dentro da casa para posterior veiculação pela televisão e na revista. A reforma da casa que serviu para a primeira Mansão Playboy, no início do ano de 1960 em Chicago, implicou a total adequação daquele espaço em um verdadeiro estúdio de tevê. Aí não havia necessidade de "janelas nem transparências. Em seu lugar, as paredes estavam cobertas de dispositivos de filmagem e projeção multimídia" (PRECIADO, 2010, p. 116). Isso porque a primeira Mansão Playboy "havia se convertido em um conjunto arquitetônico multimídia, uma nova máquina de produção de informação, prazer e subjetividade" (op. cit., p. 115), pois fazia convergir meios de comunicação (como a revista, a televisão, e, hoje, os sites na internet) que funcionavam como suporte para a experiência da (hetero) sexualidade. Preciado (op. cit., p. 45) sugere que "o habitante da Mansão Playboy é uma versão erotizada e mercantil do homem ultraconectado de McLuhan".
Para 0 autor (PRECIADO, 2010), a revista Playboy foi um acontecimento histórico-político, cujas condições de emergência foram: a expansão e consolidação do capitalismo nos Estados Unidos, pois, conforme ela, "é próprio da Playboy ter feito da pornotopia um objeto de consumo dentro do mercado liberal" (op. cit., p. 129); a superexposição imagética do corpo (feminino) através dos meios de comunicação, cujas possibilidades de registro, impressão e ampliação nas páginas da revista identificaram "novas práticas de consumo da imagem, suscitadas por novas técnicas de produção e distribuição" em sua articulação com "um conjunto de relações inéditas entre imagem, prazer, publicidade, privacidade e produção de subjetividade" (op. cit., p. 27); a reconfiguração das relações de gênero no Ocidente a partir da década de 1960, na medida em que, nas páginas da Playboy, punham-se em operação práticas discursivas - reportagens, entrevistas, editoriais - e não discursivas fotografias, ilustrações -, cujas implicações foram "desencadear um movimento pela liberação sexual masculina" e "construir um espaço autônomo não regido pelas leis sexuais e morais do matrimônio sexual" (op. cit., p. 33); e, sobretudo, a urgência do reforço da masculinidade viril heterossexual na sociedade da época, uma vez que a revista fez circular discursos destinados a construir e preservar a figura do "homem urbano, solteiro (ou divorciado), mas heterossexual" (op. cit., p. 34).

A Mansão Playboy, autêntico dispositivo pornográfico multimídia, tinha a capacidade de reunir em um só edifício, graças a uma acurada distri- 
buição vertical e horizontal e à multiplicação dos dispositivos de tecnificação do olhar, do registro e da difusão midiática da informação, espaços tradicionalmente incompatíveis: 0 apartamento do [homem] solteiro, o escritório central da revista Playboy, o estúdio de televisão, um estúdio cinematográfico, um centro de vigilância audiovisual, a residência de senhoritas e o bordel (op. cit., p. 129).

Portanto, é no bojo das considerações propostas por Preciado, seguindo as considerações de Foucault acerca das heterotopias, que "0 complexo midiático que se estendia em torno da Mansão Playboy funcionava como uma 'pornotopia'" (op. cit., p. 120). Conforme mencionado, o conceito refere-se às relações singulares entre espaço, sexualidade, prazer e tecnologia, na medida em que 0 autor propõe situar tais relações na existência de laboratórios midiáticos, nos quais se espacializa, se distribui, se comunica e se capitaliza "a subjetividade através de rigorosas técnicas de enclausuramento, superexposição, vigilância, ocultamento e produção de prazer" (op. cit., p. 131). Os espaços desses laboratórios midiáticos que espacializam a produção de prazer "emergem em um contexto histórico preciso ativando metáforas, lugares e relações econômicas preexistentes, mas singularizadas por tecnologias do corpo e da representação, que vão mudando" (op. cit., p. 121).

Preciado (op. cit., p. 120) exemplifica categorias de pornotopias do presente, entre elas as "pornotopias localizadas (...) incluindo aquelas que se deixam entrever através dos anúncios de jornal ou que, sem outra localização que não a virtual, existem em e através dos espaços cibernéticos" (grifo meu). A sugestão de que os sites de relacionamento e os aplicativos sejam abordados com o conceito de pornotopia é uma aposta teórica, que sublinha as correlações entre o uso de tecnologias de comunicação para busca de parceiros sexuais e as condições históricas que demandam a adesão dos indivíduos à sociabilidade online, inserindo o espaço da internet junto aos demais espaços de sociabilidade já existentes.

Ainda, o conceito de pornotopia possibilita aludir às diferentes condições de circulação pelo espaço urbano e suas implicações para as políticas de identidade sexual após a emergência da internet comercial. Como sugere Miskolci (2015, p. 67), a internet possibilitou a sociabilidade online "de forma anônima e relativamente segura - para pessoas que temiam retaliações sociais afastandoas da solidão e permitindo o contato efetivo e modulado com eventuais parceiros e amigos". Isso significa que, ao propor abordar a internet como heterotopia e os sites de relacionamento como pornotopias - isto é, como espaços que justapõem outros espaços urbanos incompatíveis e onde um indivíduo entra na expectativa de ser alguém diferente, espaços online ultramidiatizados, através dos quais imagens e descrições dos corpos dos usuários são instrumentos para a sociabilidade -, se está propondo considerar a hipótese de que as pornotopias do presente carregam marcas históricas das relações entre espaço e (homo)sexualidade, conforme será discutido na seção seguinte. 


\section{Espaços sexualizados}

Os modos como "0 espacial e 0 sexual constituem um ao outro" (BELL; VALENTINE, 1995, p. 2) são importantes para analisar as experiências de sexualidades não heterossexuais. "0s espaços que nós atravessamos e nos quais nós vivemos aos quais nós nos adaptamos, que nós criamos, e que às vezes reconstruímos - têm grande importância no modo como nós nos expressamos", sugere Gordon Ingram (1997, p. 27), referindo-se à relevância da habitação de espaços públicos e privados, espaços de encontro e de troca, de construção de redes de sociabilidade para pessoas não heterossexuais. É precisamente através da imbricação entre 0 espacial e 0 sexual, com ênfase nas tecnologias de comunicação, que emerge o Manhunt, caracterizado aqui como uma pornotopia. Desse modo, reformulando a colocação de David Bell e Gill Valentine, sugerese que o Manhunt é uma pornotopia na qual o espacial e o sexual constituem um ao outro, espaço em que corpos imagéticos e experiências de sexualidade empregam as mídias digitais como suporte para comunicação.

0 "mapa particular" da geografia física, para pessoas não heterossexuais, "define pontos onde amigos, amantes, parceiros sexuais em potencial e aliados podem ser encontrados, e onde o perigo pode existir", como propõem Gordon Ingram, Anne-Marie Bouthillette e Yolanda Retter (1997, p. 55). Isso acontece graças à constituição de um mapa peculiar que permite e estimula a circulação de homens gays em determinados espaços de acordo com potenciais encontros e também potenciais violências (ERIBON, 2008). Além disso, a constituição desse mapa peculiar está ligada a experiências homossexuais, que contam uma longa história de discriminação e marginalização, exigindo que diferentes espaços dentro das cidades sejam marcados, distinguidos e apropriados segundo critérios relacionados à busca por proteção contra a violência. 0 mapa peculiar construído por homens gays organiza pontos a serem habitados ou a serem evitados, definidos pelas possibilidades da vida em grupo e também pela chance de experimentar algum tipo de discriminação. Na proposição de Ingram, Bouthillette e Retter (1997, p. 55-56):

Assim como há atos sexuais e identidades pessoais relacionadas a eles, há mapas que descrevem a geografia física de uma paisagem e mapas mais subjetivos que existem nas "nossas mentes". Na experiência queer ${ }^{7}$, esse mapa de "sentido do lugar" desempenha um papel-chave, afetando como as pessoas vivem suas vidas pessoais e como elas interagem em redes sociais. Ele define pontos onde amigos, amantes, parceiros sexuais em potencial e aliados podem ser encontrados, e onde o perigo pode existir. (...) 0 mapa de cada pessoa é usualmente em parte uma autobiografia, em parte uma 
mitologia e em parte uma incorporação de tensões relativas a formas de marginalidade, como as políticas sexuais, gênero, raça, etnia ou cultura. Mas, em vez de representar uma Gestalt fielmente completa, cada mapa constitui uma página no atlas contínuo da vida individual e da história em comunidade. Ele contém dimensões emocionais, políticas e econômicas e envolve tanto indivíduos como grupos. Apesar de a dinâmica sexual sempre figurar nessas cenas, os papéis da sexualidade, e como eles são desempenhados no espaço e através do tempo, variam enormemente (grifos meus).

Portanto, quando homens gays utilizam um site de relacionamento como pornotopia, eles constroem um mapa bastante singular a partir do qual se pode estabelecer pontos de encontro com outros homens ou zonas de perigo onde pode haver violência. 0s mapas subjetivos desses homens, que organizam o conjunto de espaços disponíveis para a sociabilidade, contêm aspectos profundamente políticos e históricos, sendo produtos de um momento particular que compõe uma "página do atlas contínuo" do tempo presente. Esses mapas aqui analisados carregam traços de mapas mais amplos das relações de poder que funcionam na produção de subjetividades e de sexualidades - sexualidades que rompem com a matriz heterossexual (FOUCAULT, 2012; BUTLER, 2012) e que, portanto, estão vulneráveis à violência (DINIZ, 2014).

Bell e Valentine (1995) mostram que a criação de espaços urbanos específicos para a sociabilidade entre pessoas homossexuais, além de circunscrever certa zona de segurança contra a violência, também serve para explicitar a relação de poder existente na ideia de que todo espaço público é "sexualmente neutro". Isto é, um espaço público tido como "sexualmente neutro" quase sempre é onde atua a norma heterossexual, onde a circulação e ocupação por pessoas são livres, desde que seus comportamentos sejam condizentes com uma determinada sexualidade tida como normal. Dessa forma, as autoras mostram a importância da organização das primeiras paradas gays na América do Norte, que promoviam a circulação de pessoas não heterossexuais pelas principais ruas das grandes metrópoles dos Estados Unidos precisamente para ocupar "espaços heterossexualmente marcados". Circular pela cidade sendo assumidamente gay ou lésbica era uma atitude política para afirmar a existência, no espaço urbano, de pessoas distintivamente marcadas em relação à norma heterossexual. Lembremos do slogan de uma parada gay em Nova Iorque, no início dos anos 1990: "We are here, we are queer, get used to us": "Nós estamos aqui, nós somos gays/lésbicas, acostumem-se a nós". Na época, as relações entre espaço urbano e sexualidade eram estreitamente imbricadas: habitar determinados espaços e assumir-se como gay ou lésbica eram práticas, às vezes, inseparáveis (BELL; VALENTINE, 1995). Hoje, entretanto, com os usos da internet, a relação quase causal entre frequentar certos espaços e assumir-se como gay está dissociada. É possível, para um homem qualquer habitante de uma grande cidade brasileira, acessar sites de relacionamento como o Manhunt sem precisar necessariamente assumir-se gay. Estar online em 
um site como o Manhunt não implica em uma "saída do armário".

Assim, pode-se entender o site Manhunt enquanto um espaço dependente de uma tecnologia de comunicação, uma "arena de caça", no interior da qual se efetivam relações de disputa entre homens gays usuários do site, relações essas que têm como vórtices articuladores os corpos e as sexualidades. Uma arena midiatizada de disputa em que os corpos dos usuários são expostos por meio de imagens e na qual os prazeres são constrangidos por determinadas normalizações morais, conforme será mostrado adiante. Antes, para contextualizar a emergência da internet como uma pornotopia para aqueles que dela fazem uso, é necessário revisitar um breve inventário acerca das correlações entre espaço urbano e (homo)sexualidade. Esse breve inventário também auxiliará na compreensão dos critérios de discrição e de segurança que constituem a pornotopia do Manhunt.

\section{Onde 0 prazer acontecia}

"Apesar dos propalados efeitos libertadores da revolução sexual no Ocidente”, escreve Veriano Terto Júnior (1996, p. 93), "no que diz respeito ao sexo, os homens que fazem sexo com homens no Brasil, ao menos nas grandes cidades, nunca se ressentiram da falta de lugares para encontros (homo)sexuais". James Green (2000) e José Ronaldo Trindade (2004) sublinham a sociabilidade efervescente de São Paulo na década de 1970. Na capital paulista, "as vias públicas eram apropriadas para encontros casuais e consumação do sexo em espaços privados" (TRINDADE, 2004, p. 176). Neste contexto de certa liberalidade das possibilidades de estabelecimento de vínculos entre homens gays, apesar da plena vigência da ditadura militar, Trindade (op. cit., p. 179-180) relata 0 seguinte:

Para encontrar amigos e trocar informações sobre suas experiências, os diversos bares e boates gays também podiam servir de interessantes pontos de encontro. Mesmo os que não frequentavam tais espaços não eram ignorantes de sua existência. Portanto, longe de funcionarem como determinantes nos trajetos, esses espaços ampliavam o leque de possibilidades, os campos de ação para os homens que se entregavam a relações sexuais e/ou afetivas com outros homens na metrópole paulista.

Entretanto, Trindade (op. cit., p. 180) afirma que "0 consumo das ruas pelos homossexuais sofreu um impacto sensível com o surgimento da AIDS", entre os anos 1980 e 1990. Para ele, devido aos múltiplos discursos que culpabilizavam os homens gays, classificando-os como "grupo de risco", os encontros casuais e bastante frequentes nesses espaços urbanos de sociabilidade escassearam sobremaneira. A rua, antes narrada com alegorias de liberdade, como espaço de experimentação da sexualidade, a partir de então começa a ser associada ao perigo, ao estranho e ao desconhecido. "Logo, em vez de priorizar as ruas como espaço de conquistas, os espaços privados como bares e boates se tornaram os locais de sociabilidade por excelência" (op. cit., p. 181). 
Veriano Terto Jr. (1996, p. 93) também aponta 0 surgimento da epidemia como fator importante nessa diminuição de encontros em "locais clandestinos como banheiros públicos, cinemas, parques", mas sugere que a Aids e a nova onda de preconceitos por ela agitada não foram as únicas responsáveis.

0 reforço do circuito comercial, com locais mais institucionalizados, a repressão policial nas ruas, as mudanças no espaço urbano com a iluminação e as reformas das praças, ruas e jardins, a violência crescente de assaltos, a crise econômica que fomentou a mendicância e 0 número de pessoas vivendo na rua são alguns dos fatores que contribuíram para desmantelar grande parte deste circuito do sexo mais orgiástico, anônimo e clandestino que caracterizava grande parte do comportamento e prática sexuais de milhares de homens (op. cit., p. 93).

0 período de medo e de estranhamento dos locais públicos como espaços possíveis de estabelecimento de contatos sexuais entre homens, segundo José Ronaldo Trindade, durou apenas até a banalização da Aids. "Como se voltasse à cena com força total [nos anos 1990], estatísticas apontam que a certeza de que a AIDS havia se tornado uma doença crônica e a feminização da síndrome abrandaram os medos em relação ao sexo" (Trindade, 2004, p. 184). 0 autor menciona 0 aumento considerável no número de saunas, cinemas pornôs, boates, videolocadoras de filmes pornográficos a partir de meados da década de 1990 nas grandes cidades do Brasil. É nesse mesmo período que a internet comercial chega ao país. universidades, nas escolas, em lan houses, em cibercafés e, sobretudo, dentro de casa: espaços seguros, institucionalizados, pontos de fixidez e de proteção. Isso não significa que a frequência e 0 uso de outros espaços por parte dos homens gays tenham desaparecido. Porém, pelas condições expostas por Green, Trindade e Terto Jr., também pela emergência da internet no Brasil, pode-se dizer que os usos dos espaços de sociabilidade gay foram significativamente transformados nas últimas décadas. 0 Manhunt torna-se mais um desses espaços; é herdeiro, contudo, de uma história prévia de marginalização e estigmatização que 0 constitui indelevelmente.

\section{Onde o prazer acontece}

Em uma das entrevistas online, o usuário Kady, com 42 anos na época, respondeu o seguinte quando perguntado se frequentava saunas, parques e banheiros públicos, cinemas pornôs, videolocadoras, bares ou boates para encontrar homens parceiros sexuais, além de usar o Manhunt:

Kady: Eu acho saunas seguras, por isso continuo indo - menos, mas vou, até porque gosto muito. Não acho seguros os lugares de pegação, apesar de achar excitante.

Pesquisador: Mas já te aconteceu alguma coisa em lugar de pegação?

Kady: Não, sempre foi tranquilo, mas sempre tem o risco de encontrar alguém conhecido.
A então emergente comunicação mediada por computador acontecia no trabalho, nas
Em outro momento, a pergunta "Tu só usa o

Manhunt e o MSN Messenger para conhecer 
teus parceiros?" foi feita a Michel, de 24 anos, em outra entrevista online. Ele respondeu: "Sim, só faço isso aqui pela internet. Lá 'fora' eu não me comporto assim. Mas acho que é só uma ferramenta para me ajudar. Sem ela, eu não estaria pegando ninguém aí na rua, no shopping...”. Perguntou-se: "Em quais outros locais tu poderias ir em vez do Manhunt?". Ele respondeu:

Michel: Talvez eu estivesse indo à sauna bem mais. Ter a internet possibilita você manter contatos e fica uma coisa mais discreta, principalmente. Porque você se expõe menos pra quem tá lá fora. Porque você faz isso aqui dentro de casa, você de frente pro micro [computador]. Sem ninguém conhecido por perto. Você mantém seu sigilo.

Na mesma direção, o entrevistado Wilde, de 32 anos, respondeu algo semelhante à mesma pergunta:

Wilde: Nunca fui em sauna, só a bares e boates [gays]. Uso a internet por uma questão de discrição (...) uma maneira de não expor a minha pessoa.

Os trechos de entrevistas mostram que 0 Manhunt é o espaço principal, e às vezes exclusivo, que esses homens utilizam para encontrar outros homens. Como já foi sugerido, é possível estar online no Manhunt e permanecer dentro de casa, em frente ao computador, para conhecer outros homens. Talvez seja por essa razão que os usos de sites de relacionamento na internet renovem as dicotomias dentro-fora, público-privado, pornográfico-obsceno (SIBILIA, 2015): estar no interior de um espaço privado e seguro, online no Manhunt, e ainda assim poder conhecer outros homens (os quais, por sua vez, também poderão estar dentro de suas casas, ou em seus locais de trabalho, ou em lan houses). Ao passo que "estar fora" significa sair dos espaços privados e inserirse na tessitura dos espaços urbanos, ir à rua, mover o corpo para o espaço público e aí circular. Assim como na definição de "armário", que só existe mediante "uma relação distintivamente indicativa entre homossexualidade e mapeamentos mais amplos do segredo e da revelação, do público e do privado" (SEGDWICK, 2007, p. 26), com 0 uso dos sites de relacionamento ganha reforço a ideia de que, se um homem quer encontrar outros parceiros afetivos e sexuais, ele não precisa "ir pra fora", sair do seu espaço privado; ele não é mais obrigado a circular pelo espaço público como acontecia antes do surgimento da internet comercial no Brasil. De acordo com Kady, a vulnerabilidade à violência potencialmente presente em espaços do circuito institucionalizado de sociabilidade gay como saunas, parques e banheiros públicos, cinemas pornôs e videolocadoras de filmes eróticos - também desencoraja a circulação nesses locais. De certa maneira, no entanto, esses excertos sugerem que a internet, em especial os sites de relacionamento por ela oferecidos, é um espaço importante para esses homens, pois é ao qual recorrem com maior frequência e talvez com exclusividade para conhecerem parceiros.

"As vizinhanças [neighbourhoods] queer são refúgios efetivos contra a homofobia, ou são 
apenas lugares onde há muitas mulheres

lésbicas e homens gays?", perguntam-se Ingram, Bouthillette e Retter (1997, p. 14). É possível sugerir que a violência expressa através de preconceitos e discriminações em relação às sexualidades não heterossexuais é, ela própria, um elemento constitutivo da sociabilidade gay. Ingram, Bouthillette e Retter (1997) apresentam a homofobia como um marcador importante para constituição de espaços habitados por pessoas queer, sugerindo que tais espaços deveriam ser, ou poderiam ser, "refúgios efetivos contra a homofobia". Muito embora a constituição de espaços urbanos habitados majoritariamente por pessoas gays tenha desempenhado um papel fundamental na organização política dos movimentos de afirmação das identidades sexuais, as análises dos mapas subjetivos dos usuários do Manhunt mostram que a ideia de que os espaços sabidamente habitados por homens gays (como é o caso do Manhunt, por exemplo) seriam refúgios contra a homofobia é, em alguma medida, uma ficção.

Os excertos a seguir, de perfis online de três diferentes usuários, mostram os conflitos que a sociabilidade online produz entre os homens que usam a pornotopia do Manhunt:

Não curto bichinhas, afeminados, fashionistas, fãs de Madonna, prepotentes, arrogantes, pessoas abaixo de 18 e acima de 29 anos. Se vocês não tem foto, não vou responder. Todos os demais são bem-vindos... [PERFIL 1]

Não procuro nada... Não curto gordos... Nem gordinhos... Nem afeminados e não to a fim de ficar com gente casada. E se não aceita um "não" como possível resposta, NÃO entre em contato. [PERFIL 2]

Leio 0 perfil de muita gente aqui nesse site $\mathrm{e}$ fico as vezes assustado e impressionado com as demonstrações de preconceito e intolerância. Quanta incompreensão! Não tenho receio e nem restrição com nada e com ninguém. $A$ vida me ensinou que cada um é cada um. Que a riqueza do mundo é a diversidade. Não tenho nada contra gordos, afeminados, passivos, veIhos e travestis. 0 mundo já me discrimina por ser gay e se estão aqui nesse site também deveriam se sentir assim. [PERFIL 3]

Os trechos anteriormente citados apontam vários elementos para pensar os aspectos violentos que emergem no seio da sociabilidade do site. Em primeiro lugar, mencionam enfrentamentos importantes entre os usuários do Manhunt, questionando a qualidade do relacionamento existente entre eles. Tais enfrentamentos são, geralmente, marcados pela negação dos vínculos (a palavra "não" é reiteradamente utilizada) com certos indivíduos que carregam marcas corporais. Essa postura é tida como "demonstrações de preconceito e de intolerância" que, no limite, se traduzem em "receio" e "restrição". A crítica formulada no terceiro trecho de perfil remete às dimensões de violência, as quais acabam se tornando um elemento constituinte dos próprios "relacionamentos" possibilitados pelo uso do site. Pode-se sugerir que essa pornotopia, longe de ser um espaço de proteção, é ela própria marcada por relações de exclusão.

Os dois primeiros usuários enumeram os sujeitos indesejáveis para a maioria dos homens que 
usam 0 site Manhunt. Pelo contexto em que esses sujeitos são designados, supõe-se que são eles os alvos do "preconceito" e da "intolerância" no espaço do site. A designação desses "outros", alheios e avessos a determinadas conformidades corpóreas, geracionais e de gênero, acaba por posicioná-los em uma zona de exclusão dos mapas peculiares dos usuários do Manhunt; eles são estranhos e, como tal, estão sujeitos à violência. A menção dos indivíduos indesejáveis na sociabilidade online é importante para sinalizar 0 aspecto central da violência das relações entre os homens gays usuários do Manhunt. No trecho de perfil online anteriormente trazido, aquele usuário ainda sugere que "o mundo me discrimina por ser gay" e exorta os demais: "se estão aqui nesse site também deveriam se sentir assim".

Sugere-se que os trechos de perfis e de entrevistas aqui apresentados sinalizam que a violência está, de certa maneira, incorporada na dinâmica social do Manhunt. Nesse espaço, encontram-se mecanismos de exclusão que, longe de constituírem o site como um refúgio contra a discriminação, acabam por tornálo uma superfície de luta entre aqueles que, supostamente, seriam atravessados por uma mesma identidade (a identidade gay). Portanto, não se trata de assumir tão rapidamente que a utilização de sites de relacionamento garanta, ou que pelo menos aumente, a segurança dos usuários contra o risco de episódios de violência; trata-se, por outro lado, de vislumbrar na própria sociabilidade ultraconectada marcas de violência e de assinalar as condições de exercício de tais práticas.

\section{Notas finais - ou "... o resto está no mesmo barco"}

Na tentativa de explorar uma abordagem possível da relação entre mídias digitais, espaço e sexualidade, propôs-se tomar a rede mundial de computadores como uma heterotopia (LEMOS, 2010; FOUCAULT, 2013). Tomando especificamente 0 site de relacionamento Manhunt, voltado para homens gays, sugeriu-se que este espaço online poderia ser entendido como uma pornotopia do presente (PRECIADO, 2010). Por meio do conceito de pornotopia, procurou-se sublinhar 0 uso articulado das possibilidades técnicas da conexão através da internet (na forma de sites de relacionamento como o Manhunt e, mais recentemente, nos aplicativos geolocalizados) e a busca por parceiros afetivos e sexuais.

Tal articulação é constituída por condições históricas, políticas e culturais que dizem respeito à experiência das sexualidades não heterossexuais. Partindo de trechos de entrevistas feitas com usuários do Manhunt, reconstituiuse uma breve história possível das relações entre (homo)sexualidade e espaço, salientando que essas relações vêm sendo atravessadas ora pela demanda por visibilidade, ora pela exigência de discrição por sexualidade gay. Tanto a demanda por visibilidade, como é o caso das reivindicações das paradas gays, quanto 
a exigência por discrição, como fazem alguns usuários do Manhunt, são estratégias contra a violência por discriminação. Através dos trechos de entrevistas, mostrou-se que os usuários do site escolhem utilizar da tecnologia da internet para busca de parceiros, de modo a garantir segurança e discrição; porém, sugeriu-se também que a dinâmica social produzida no e pelo Manhunt é, indelevelmente, constituída por mecanismos de exclusão entre seus usuários.

Cabem ainda algumas considerações sobre os usos dos aplicativos geolocalizados. André Lemos (2010) já abordou as relações entre mídias locativas, anonimato e insegurança, muito embora sem considerar experiências de sexualidade. Entretanto, junto com o autor, é possível dizer que 0 uso dos aplicativos geolocalizados por homens gays na busca de parceiros sexuais e afetivos se insere no bojo da sociedade de controle (DELEUZE, 1992), na qual a vigilância sobre os indivíduos (e sobre seus corpos) é tanto maior quanto é maior sua circulação no espaço urbano.

0 uso dos aplicativos geolocalizados estimula a circulação dos indivíduos na medida em que quanto maior o deslocamento pelo tecido urbano, maior a chance de ser visto online pelos demais usuários geograficamente próximos (há um desestímulo em permanecer sempre em um mesmo ponto); e quanto maior a probabilidade de ser visto online, maior é a chance de encontrar um parceiro (se os aplicativos são usados em múltiplos pontos, também múltiplos outros usuários podem estar próximos). Tal circulação “implica em maior liberdade informacional pelo espaço urbano, mas também uma maior exposição a formas (sutis e invisíveis) de controle, monitoramento e vigilância" (LEMOS, 2010, p. 62). É curioso que precisamente homens gays façam uso deste tipo de tecnologia de controle: "Nesse regime global de insegurança, há alguns (o 'outro') que devem ser vigiados e outros não", desafia Lemos (op. cit., p. 69).

Em uma entrevista, o usuário do Manhunt Mad Dog, de 24 anos, disse o seguinte: "Tirando os lindos que conseguem arrumar namorado no posto de gasolina, o resto todos [sic] estão mais ou menos no mesmo barco". Perguntou-se, "Qual é esse barco?", ao que ele respondeu: "De tentar, tentar, tentar em todo e qualquer tipo de mídia". Essa sugestão indica que os usos possíveis das tecnologias de comunicação para busca de parceiros afetivos e sexuais estão constrangidos por condições culturais e históricas vinculadas à significação dos corpos, aos padrões estéticos, às normas de gênero e de sexualidade - entre outros marcadores. Essa fala sugere que a análise cultural dos usos das mídias digitais como suporte para a sociabilidade gay deve considerar as formas como a tecnologia adere às, e atualiza as, demandas pela busca do "amor que não ousa dizer seu nome", como escreveu Oscar Wilde - uma sexualidade historicamente alijada e estigmatizada sob os signos da patologia, do crime e do desvio.

É produtivo o fato de Mad Dog referir-se às mídias digitais como um "barco", espaço onde estão os 
homens gays que tentam encontrar parceiros afetivos e sexuais. Pois, segundo Foucault (2013, p. 30), esse "pedaço de espaço flutuante" é a grande "reserva de imaginação" das civilizações ocidentais; sem ela, "a espionagem substitui a aventura, e a truculência dos policiais, a beleza ensolarada dos corsários".

\section{Referências}

BELL, David. VALENTINE, Gill. Introduction: Orientations. In: BELL, David. VALENTINE, Gill. (Orgs.). Mapping Desire. New York: Routledge, 1995. p. $1-30$.

BUTLER, Judith. Cuerpos que inportán - sobre los límites discursivos del sexo. Buenos Aires: Paidós, 2012. DEFÉRT, Daniel. Posfácio. In: FOUCAULT, Michel. 0 corpo utópico; As heterotopias. São Paulo: n-1 edições, 2013. p. 33-55.

DELEUZE, Gilles. Conversações. São Paulo: Editora 34, 1992.

DINIZ, Débora. 0 escândalo da homofobia - imagens de vítimas e sobreviventes. Revista ECOMPós, Rio de Janeiro, vol. 17, n. 1. p. 1-19. 2014.

DUARTE, Fábio. FIRMINO, Rodrigo. Espaço, visibilidade e tecnologias: (Re)caracterizando a experiência urbana. In: BRUNO, Fernanda. KANASHIR0, Marta. FIRMINO, Rodrigo. (Orgs.). Vigilância e visibilidade: espaço, tecnologia e identificação. Porto Alegre: Sulina, 2010. p. 94-112.

ERIBON, Didier. Reflexões sobre a questão gay. Rio de Janeiro: Companhia de Freud, 2008.

FOUCAULT, Michel. A história da sexualidade I - a vontade de saber. Rio de Janeiro: Graal, 2012. . 0 corpo utópico; As heterotopias. São Paulo: n-1 edições, 2013.
GREEN, James. Além do carnaval - A

homossexualidade masculina no Brasil do século XX. São Paulo: UNESP, 2000.

INGRAM, Gordon Brent. Lost in space: queer theory and community activism at the Fin-de-Millinére. In: INGRAM, Gordon. BOUTHILLETTE, Anne-Marie. RETTER, Yolanda. (Orgs.). Queers in Space Communities, Public Spaces, Sites of resistance. Seattle: Bay Press, 1997. p. 3-16. . Marginality and the landscapes of erotic alie(n)ations. In: INGRAM, Gordon. BOUTHILLETTE, Anne-Marie. RETTER, Yolanda. (Orgs.). Queers in Space - Communities, Public Spaces, Sites of resistance. Seattle: Bay Press, 1997. p. 27-53.

INGRAM, Gordon. BOUTHILLETTE, Anne-Marie. RETTER, Yolanda. Narrative of place: subjective and collective. In: INGRAM, Gordon. BOUTHILLETTE, Anne-Marie. RETTER, Yolanda. (Orgs.). Queers in Space - Communities, Public Spaces, Sites of resistance. Seattle: Bay Press, 1997. p. 55-60.

LEMOS, André. Mídias locativas e vigilância. Sujeito inseguro, bolhas digitais, paredes virtuais e territórios informacionais. In: BRUNO, Fernanda. KANASHIRO, Marta. FIRMINO, Rodrigo. (Orgs.). Vigilância e visibilidade: espaço, tecnologia e identificação. Porto Alegre: Sulina, 2010. p. 61-93.

MAFFESOLI, Michel. 0 mistério da conjunção ensaios sobre comunicação, corpo e socialidade. Porto Alegre: Sulina. 2005.

MISKOLCI, Richard. "Discreto e fora do meio" - Notas sobre a visibilidade sexual contemporânea. Cadernos pagu, Campinas, vol. 1, n. 44, p. 61-90, 2015.

PELÚCIO, Larissa. Narrativas infiéis: notas metodológicas e afetivas sobre experiências das masculinidades em um site de encontros para pessoas casadas. Cadernos pagu, Campinas, vol. 1, n. 44, p. 31-60, 2015. 
PRECIADO, Beatriz. Pornotopía - Arquictetura y sexualidad en "Playboy" durante la guerra fría. Barcelona: Anagrama, 2010.

RECUERO, Raquel. Redes sociais na internet. Porto Alegre: Meridional, 2009.

SEDGWICK, Eve Kosofsky. Epistemologia do armário. Cadernos pagu, Campinas, vol. 1, nº 28, p. 19-54, 2007.

SIBILIA, Paula. A nudez autoexposta na rede: deslocamentos da obscenidade e da beleza?. Cadernos pagu, Campinas, vol. 1, nº 44, p. 171-198, 2015.

TERTO JR., Veriano. Homossexuais soropositivos, soropositivos homossexuais: questões da homossexualidade masculina em tempos de AIDS. In: PARKER, Richard. BARBOSA, Regina. (Orgs.). Sexualidades Brasileiras. Rio de Janeiro: Relume Dumará, 1996. p. 90-105.

TRINDADE, José Ronaldo. Construção de identidades homossexuais na era da AIDS. In: UZIEL, Anna Paula; RIOS, Luis Felipe; PARKER, Richard. Construções de sexualidade: gênero, identidade e comportamento em tempos de AIDS. Rio de Janeiro, Pallas, 2004. p. 169-199.

VAZ, Paulo. Mediação e tecnologia. In: MARTINS, Francisco Menezes. SILVA, Juremir Machado. (Orgs.).

A genealogia do virtual: comunicação, cultura e tecnologias do imaginário. Porto Alegre: Sulina, 2004. p. 216-238.

ZAG0, Luiz Felipe. 'Armários de vidro' e 'corpos sem cabeça' na biossociabilidade gay online. Interface, Botucatu, v. 17, nº 45, p. 419-432, 2013. 


\begin{tabular}{|c|c|}
\hline $\begin{array}{l}\text { Pornotopies - space, } \\
\text { media and sexuality }\end{array}$ & $\begin{array}{l}\text { Pornotopías - espacio, } \\
\text { medias y sexualidad }\end{array}$ \\
\hline $\begin{array}{l}\text { Abstract } \\
\text { It is analyzed the articulation among an online } \\
\text { social network, urban space and experiences of } \\
\text { (homo)sexuality, underscoring the communicative } \\
\text { potential brought by internet and underlying the } \\
\text { cultural and historical vestiges of gay sociability. } \\
\text { Excerpts of online profiles and interviews with the } \\
\text { users of the site are used. Internet is taken as a } \\
\text { heterotopy, and specifically the online social network } \\
\text { is approached by the concept of pornotopy. It is } \\
\text { mentioned the relations among security, discretion } \\
\text { and violence in the occupation of certain spaces. The } \\
\text { conclusion suggests that the uses of internet made } \\
\text { by the interviewed men respond to constritions of a } \\
\text { historically stigmatized sexuality. } \\
\text { Keywords } \\
\text { Sexuality. Urban Space. Online Social Network. }\end{array}$ & $\begin{array}{l}\text { Resumen } \\
\text { Analiza las relaciones entre un sitio de redes } \\
\text { sociales, el espacio urbano y las experiencias } \\
\text { de (homo)sexualidad, privilegiando el potencial } \\
\text { comunicativo interpuesto por la Internet y } \\
\text { destacando las marcas culturales e históricas de } \\
\text { la sociabilidad gay. Utiliza fragmentos de perfiles } \\
\text { en línea y de entrevistas con los usuarios del } \\
\text { sitio. Toma la Internet como una heterotopía, y } \\
\text { específicamente el sitio de redes sociales és enfocado } \\
\text { por el concepto de pornotopía. Menciona la relación } \\
\text { entre la seguridad, la discreción y la violencia } \\
\text { en la ocupación de ciertos espacios. Se llega a la } \\
\text { conclusión de que los usos de Internet realizado por } \\
\text { los entrevistados responden a las restricciones de } \\
\text { una sexualidad históricamente estigmatizado. } \\
\text { Palabras clave }\end{array}$ \\
\hline
\end{tabular}




\section{Expediente}

A revista E-Compós é a publicação científica em formato eletrônico da Associação Nacional dos Programas de Pós-Graduação em Comunicação (Compós). Lançada em 2004, tem como principal finalidade difundir a produção acadêmica de pesquisadores da área de Comunicação, inseridos em instituições do Brasil e do exterior.

\section{E-COMPÓS I www.e-compos.org.br I E-ISSN 1808-2599}

Revista da Associação Nacional dos Programas de Pós-Graduação em Comunicação.

Brasília, v.19, n.3, set./dez. 2016.

A identificação das edições, a partir de 2008, passa a ser volume anual com três números.

Indexada por Latindex I www.latindex.unam.mx

\section{CONSELHO EDITORIAL}

Alexandre Farbiarz, Universidade Federal Fluminense, Brasil Alexandre Rocha da Silva, Universidade Federal do Rio Grande do Sul, Brasil Ana Carolina Escosteguy, Pontifícia Universidade Católica do Rio Grande do Sul, Brasil Ana Carolina Rocha Pessôa Temer, Universidade Federal de Goiás, Brasil Ana Regina Barros Rego Leal, Universidade Federal do Piauí, Brasil Andrea França, Pontifícia Universidade Católica do Rio de Janeiro, Brasil André Luiz Martins Lemos, Universidade Federal da Bahia, Brasil Antonio Carlos Hohlfeldt, Pontifícia Universidade Católica do Rio Grande do Sul, Brasil Arthur Ituassu, Pontifícia Universidade Católica do Rio de Janeiro, Brasil Álvaro Larangeira, Universidade Tuiuti do Paraná, Brasil Ângela Freire Prysthon, Universidade Federal de Pernambuco, Brasil César Geraldo Guimarães, Universidade Federal de Minas Gerais, Brasil Cláudio Novaes Pinto Coelho, Faculdade Cásper Líbero, Brasil Daisi Irmgard Vogel, Universidade Federal de Santa Catarina, Brasil Denize Correa Araujo, Universidade Tuiuti do Paraná, Brasil

Eduardo Antonio de Jesus, Pontifícia Universidade Católica de Minas Gerais, Brasil Daniela Zanetti, Universidade Federal do Espirito Santo, Brasil

Eduardo Vicente, Universidade de São Paulo, Brasil

Elizabeth Moraes Gonçalves, Universidade Metodista de São Paulo, Brasil Erick Felinto de Oliveira, Universidade do Estado do Rio de Janeiro, Brasil Francisco Elinaldo Teixeira, Universidade Estadual de Campinas, Brasil Francisco Paulo Jamil Almeida Marques, Universidade Federal do Paraná, Brasil Gabriela Reinaldo, Universidade Federal do Ceará, Brasil

Goiamérico Felício Carneiro Santos, Universidade Federal de Goiás, Brasil Gustavo Daudt Fischer, Universidade do Vale do Rio dos Sinos, Brasil Herom Vargas, Universidade Municipal de São Caetano do Sul, Brasil Itania Maria Mota Gomes, Universidade Federal da Bahia, Brasil Janice Caiafa, Universidade Federal do Rio de Janeiro, Brasil Jiani Adriana Bonin, Universidade do Vale do Rio dos Sinos, Brasil
José Afonso da Silva Junior, Universidade Federal de Pernambuco, Brasil José Luiz Aidar Prado, Pontifícia Universidade Católica de São Paulo, Brasil Juçara Gorski Brittes, Universidade Federal de Ouro Preto, Brasil Kati Caetano, Universidade Tuiuti do Paraná, Brasil Lilian Cristina Monteiro França, Universidade Federal de Sergipe, Brasil Liziane Soares Guazina, Universidade de Brasilia, Brasil Luíza Mônica Assis da Silva, Universidade de Caxias do Sul, Brasil Luciana Miranda Costa, Universidade Federal do Pará, Brasil Malena Segura Contrera, Universidade Paulista, Brasil Monica Martinez, Universidade de Sorocaba, Brasi Maria Ataide Malcher, Universidade Federal do Pará, Brasil Marcia Tondato, Escola Superior de Propaganda e Marketing, Brasil Marcel Vieira Barreto Silva, Universidade Federal da Paraíba, Brasil Maria Clotilde Perez Rodrigues, Universidade de São Paulo, Brasil Maria das Graças Pinto Coelho, Universidade Federal do Rio Grande do Norte, Brasil Mauricio Ribeiro da Silva, Universidade Paulista, Brasil

Mauro de Souza Ventura, Universidade Estadual Paulista, Brasil Márcio Souza Gonçalves, Universidade do Estado do Rio de Janeiro, Brasil Micael Maiolino Herschmann, Universidade Federal do Rio de Janeiro, Brasil Mirna Feitoza Pereira, Universidade Federal do Amazonas, Brasil Nísia Martins Rosario, Universidade Federal do Rio Grande do Sul, Brasil Potiguara Mendes Silveira Jr, Universidade Federal de Juiz de Fora, Brasil Regiane Regina Ribeiro, Universidade Federal do Paraná, Brasil Rogério Ferraraz, Universidade Anhembi Morumbi, Brasil Rose Melo Rocha, Escola Superior de Propaganda e Marketing, Brasil Rozinaldo Antonio Miani, Universidade Estadual de Londrina, Brasil Sérgio Luiz Gadini, Universidade Estadual de Ponta Grossa, Brasil Simone Maria Andrade Pereira de Sá, Universidade Federal Fluminense, Brasil Veneza Mayora Ronsini, Universidade Federal de Santa Maria, Brasil Walmir Albuquerque Barbosa, Universidade Federal do Amazonas, Brasil

\section{CONSELHO CIENTÍFICO}

Cristiane Freitas Guttreind, Pontifícia Universidade Católica do Rio Grande do Sul, Brasil Eduardo Morettin, Universidade de São Paulo, Brasil Felipe Costa Trotta, Universidade Federal Fluminense, Brasil Irene de Araújo Machado, Universidade de São Paulo, Brasil

\section{COMISSÃO EDITORIAL}

Eduardo Antonio de Jesus, Pontifícia Universidade Católica de Minas Gerais, Brasil Osmar Gonçalves dos Reis Filho, Universidade Federal do Ceará, Brasil

\section{CONSULTORES AD HOC}

Geane C. Alzamora, Universidade Federal de Minas Gerais, Brasil Teresinha Cruz Pires, Pontifícia Universidade Católica de Minas Gerais, Brasil

\section{EQUIPE TÉCNICA}

ASSISTENTE EDITORIAL Márcio Zanetti Negrini

REVISÃO DE TEXTOS Press Revisão

EDITORAÇÃO ELETRÔNICA Roka Estúdio

IMAGEM DE CAPA Silas de Paula

\section{COMPÓS I www.compos.org.br}

Associação Nacional dos Programas de Pós-Graduação em Comunicação

Presidente

Edson Fernando Dalmonte

Programa de Pós-Graduação em Comunicação

e Cultura Contemporânea - UFBA

edsondalmonte@uol.com.br

Vice-presidente

Cristiane Freitas Gutfreind

Programa de Pós-Graduação em Comunicação Social - PUC-RS cristianefreitas@pucrs.br

Secretário-Geral

Rogério Ferraraz

Programa de Pós-Graduação em Comunicação

Universidade Anhembi Morumbi

rogerioferraraz@anhembimorumbi.edu.br

CONTATO I revistaecompos@gmail.com 